\title{
CALCULATION OF THE SPATIAL DISTRIBUTION OF WATER TEMPERATURE AND SALINITY IN THE ACTIVE LAYER OF THE BLACK SEA BY SATELLITE DATA
}

\section{Andrii Sryberko ${ }^{1}$}

DOI: https://doi.org/10.30525/978-9934-588-11-2_21

To solve the many practical problems, it is necessary to use vertical distribution of hydrological characteristics of the marine environment. Today there isn't an easy way to get a in situ data for evaluation of the vertical distribution [1, p. 20].

Indirect definitions of the vertical distribution of water temperature through the development of various methods for the calculation of the distribution of water temperature on the vertical are used to date $[1, \mathrm{p} .10]$.

Main purpose of this work is to estimate an ability of using of satellite data for calculation of the spatial distribution of thermohaline characteristics (on the example of the Black Sea).

Calculations of the spatial distribution of water temperature and salinity in the active layer of the Black Sea by satellite data are founded on the «Method of calculation of the vertical distribution of thermohaline characteristics by satellite-based Information (on the example of the Black Sea)» (hereinafter referred to as the Method) created by us in 2016. This Method was presented at the conference in 2016 [2].

In undertaking this work the developed Method [2] was significantly completed with new equations for calculating the vertical distribution of water temperature, salinity and sound speed in water, criteria for calculations, corrections for the temperature of the Water, which significantly improves the accuracy of the calculations of the vertical distribution of water temperature and salinity in the active layer of the Black Sea by satellite data.

Study of vertical distribution of water temperature and salinity in the Black Sea were carried out in the deep-water part sea at standard levels $(0,10,20,25,30,50$ meters) in spring - autumn period. This area of research is represented by the highest number of measurements and is included in the Main Black Sea current zone.

In the process of research, the following tasks were solved:

- the determination of statistical dependences between the values of water temperature at the neighboring levels in the Black Sea according to the averaged data of water temperature and the creation of regression equations;

- the determination of statistical dependences between the values of water temperature, depth and sound speed in water;

- the determination of statistical dependences between the values of water salinity, water temperature, sound speed in water and hydrostatic pressure;

\footnotetext{
${ }^{1}$ Hydroacoustics Branch of Institute of Geophysics of National Academy of Sciences of Ukraine, Ukraine
} 
- estimation of the possibility of calculating the vertical distribution of water temperature in the Black Sea according to developed regression equations based on satellite information;

- estimation of the possibility of calculating the vertical distribution of the sound speed by the values of water temperature calculated according to developed regression equations based on satellite information;

- estimation of the possibility of calculating the salinity of water by the values of water temperature, sound speed in water and hydrostatic pressure calculated according to developed regression equations;

- development of a method for calculating of the spatial (three-dimensional) distribution of the thermohaline characteristics in the active layer of the Black Sea on acoustic and satellite data.

The local calculation of the vertical distribution of water temperature and salinity in the Black Sea by acoustic and satellite data in the layer 0-50 meters at several stations can be easily carried out by applying the developed equations. But if the whole water area of the Black Sea should be counted, this process is very time consuming.

Therefore, we designed a prototype of a computer program (hereinafter referred to as the Program) for the calculating of the vertical distribution of water temperature and salinity in the Black Sea by acoustic and satellite data.

The Program automatically determines where and by what equations the vertical distribution of the thermohaline characteristics in the active layer of the Black Sea can be calculated.

The initial data for the calculations are only daily satellite data of the sea surface temperature and the month of the year.

Research results from the calculations of the vertical distribution of water temperature in the Black Sea by satellite data at standard levels in spring - autumn period showed that the change in the vertical profile of water temperature obeys the exponential law of distribution. The linear law of distribution is dominated when the deviation of sea surface temperatures from climatic water temperature values is more than $\pm 2{ }^{\circ} \mathrm{C}$.

Water temperature corrections are introduced on the levels of 10, 20, 25 meters during spring - summer, and in autumn - on the levels 10,20,25, 50 meters.

To visualize the results of the calculations by the Program the maps of the spatial distribution of water temperature and salinity at standard levels and zonal section (latitude $43.8^{\circ} \mathrm{N}$ ) for 08.07 .2018 were built. 

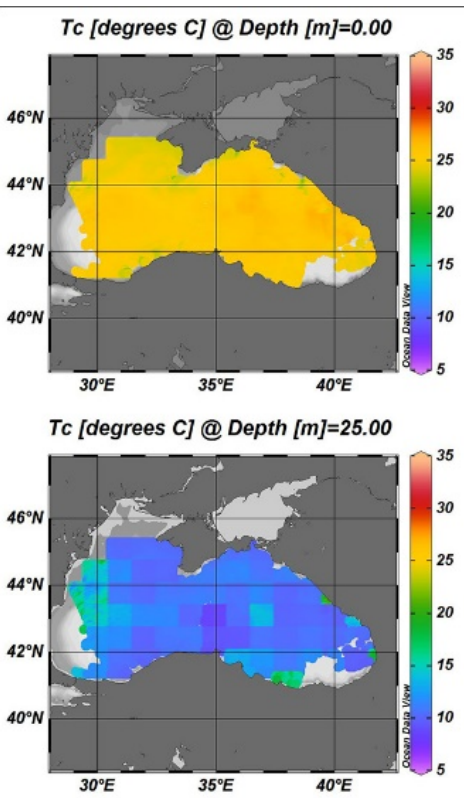

a

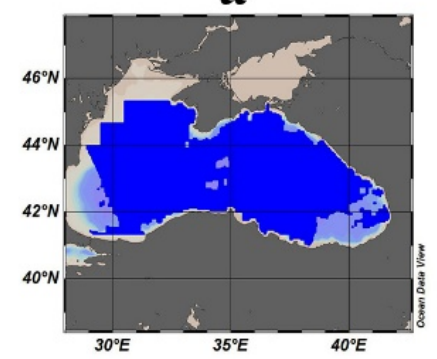

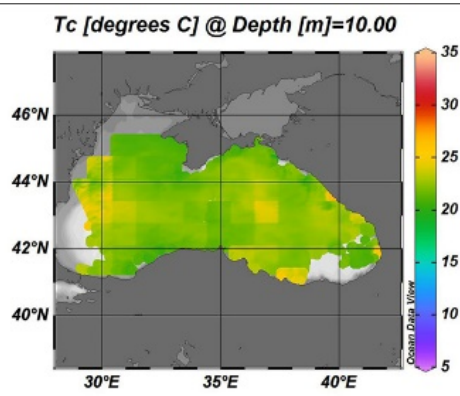

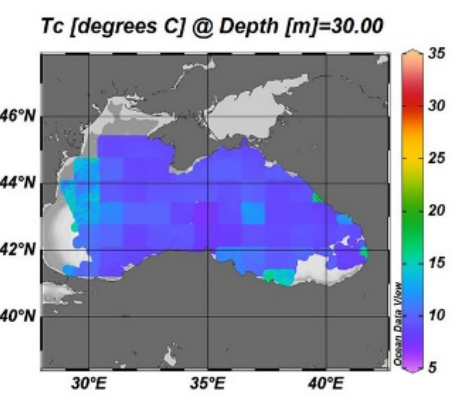

Sc [PSS] @ Depth $[\mathrm{m}]=0.00$

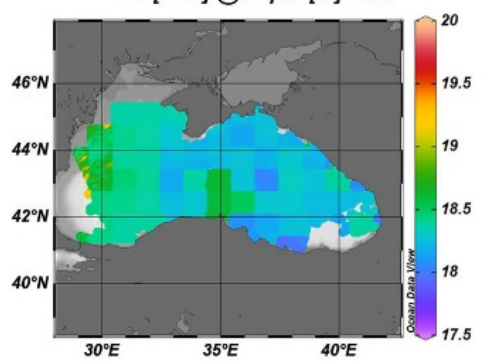

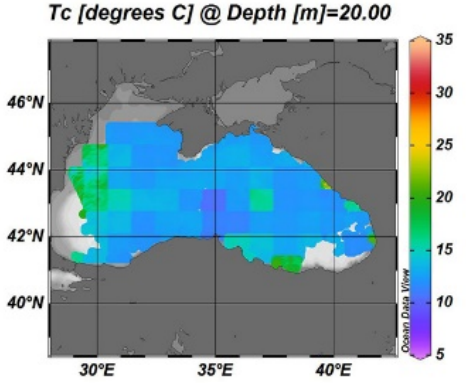

Tc [degrees C] @ Depth [m]=50.00

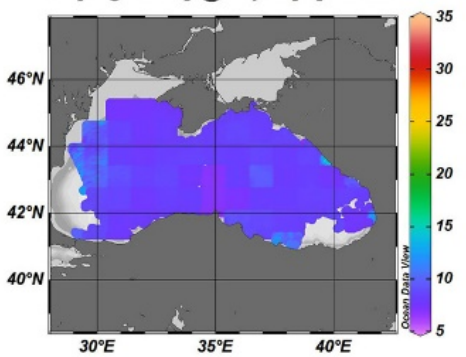

Sc [PSS] @ Depth [m]=50.00

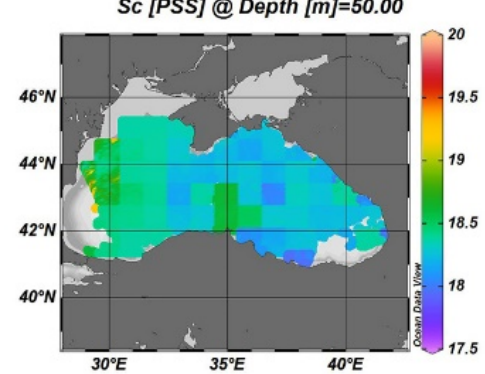

Figure 1. Maps of spatial distribution of calculated water temperature $\left(T_{c}\right)$ at the standard levels and salinity $\left(S_{c}\right)$ at a depth of $0,50 \mathrm{~m}$ in the Black Sea for 08.07.2018. Map (a) is map of the distribution of satellite data for calculation [3]

On the map (a) (see Figure 1) the initial satellite data were the daily data on satellite measurements of the Black Sea water surface temperature with $4 \mathrm{~km}$ step on latitude and longitude, measured companion NASA (Terra MODIS) [3].

The results of calculations of zonal section (latitude $43.8^{\circ} \mathrm{N}$ ) in the Black Sea for 08.07.2018 are presented in Figure 2. 

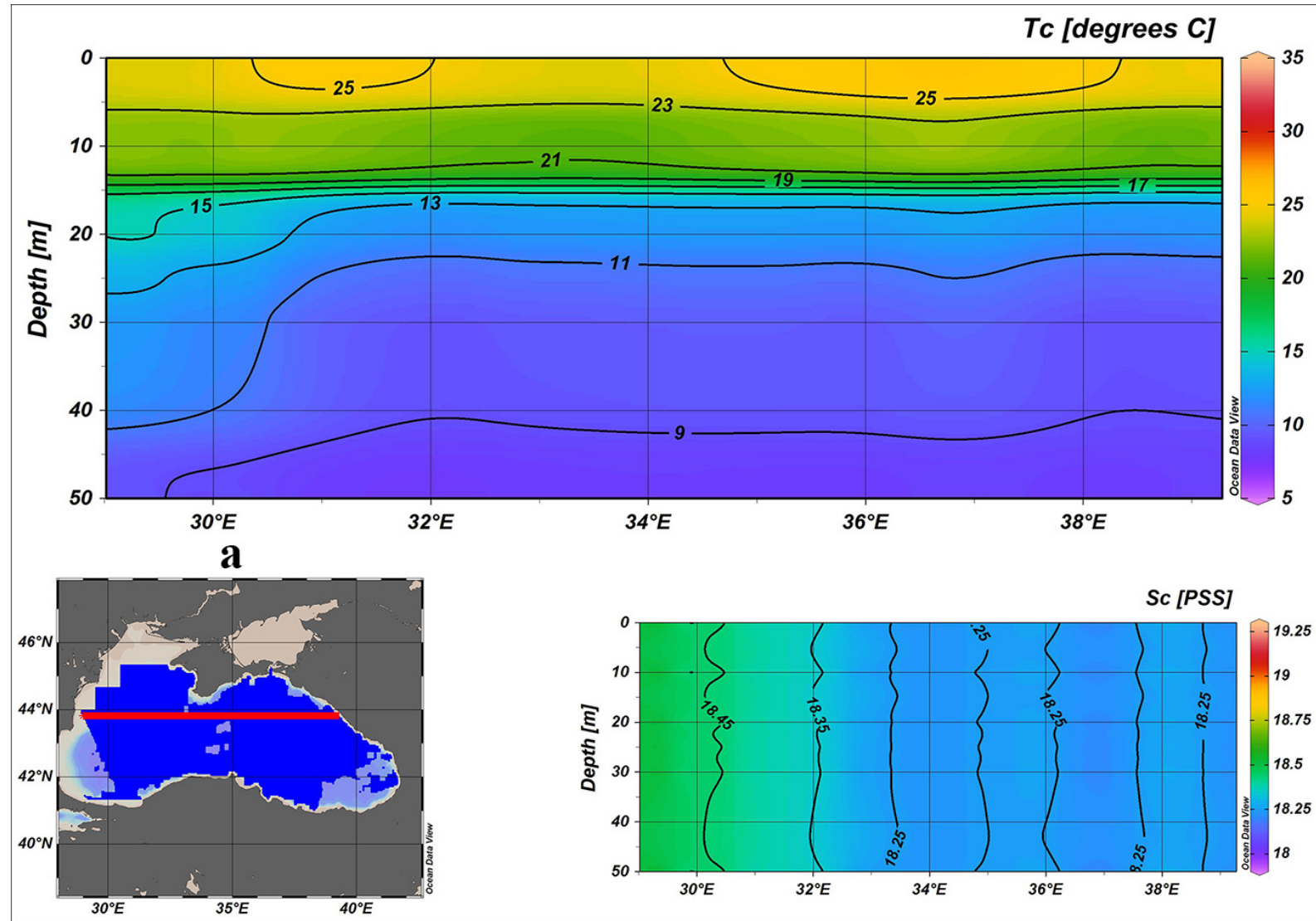

\section{Figure 2. Distribution of calculated of water temperature $\left(T_{c}\right)$ and salinity $\left(S_{c}\right)$ on zonal section (latitude $43.8^{\circ} \mathrm{N}$ ) in the Black Sea for 08.07.2018. The map shows the location of section in the Black Sea}

Figures 1 and 2 are built using computer program Ocean Data View (ODV) that is intended for the interactive exploration and graphical display of oceanographic and other geo-referenced profile, trajectory or time - series data [4].

Designed by us, the prototype of a computer program to calculate the vertical distribution of the thermohaline characteristics in the active layer of the Black Sea by satellite data could serve as a basis for the establishment of a «Operational Forecast System of the thermohaline characteristics in the Black Sea « (OFS). With the help of which the dynamics of characteristics and effects of their change on hydrobiological, hydrochemical, hydrophysical processes in the Black Sea and the ecosystem of the sea in general can be evaluated.

In our opinion the developed method for calculating of the spatial (threedimensional) distribution of the thermohaline characteristics by acoustic and satellite data can be applied to others water area of the World Ocean taking into account their hydrological conditions.

\section{References:}

1. Andrianova, O. R., Skipa, M. I., Sryberko, A. V., \& Stepanova, Y. V. (2015). Otsenka vozmozhnosti rascheta vertikal'nogo raspredeleniya temperatury vody $\mathrm{v}$ Chernom more po sputnikovym dannym [Estimation of ability of vertical temperature distribution's calculation for the Black sea's water by satellite data]. Herald ONU. Geography and Geology, vol. 20, no. 4, pp. 9-21. 
2. Andrianova, O., Batyrev, O., Skipa, M., \& Sryberko, A. (Eds.) (2016). The Method of calculation of the vertical distribution of thermohaline characteristics by satellite-based Information. Proceedings of the Black Sea from Space Workshop (Romania, Constanta, September 26-27, 2016), European Space Agency. Retrieved from: https://nikal.eventsair.com/QuickEventWebsitePortal/ black-sea-from-space-2016/black-sea

3. NASA's OceanColor Web (2019). National Aeronautics and Space Administration, OceanColor Web. Retrieved from: https://oceancolor.gsfc.nasa.gov/cgi/13 (accessed August 2019).

4. Schlitzer, R. (2019). Ocean Data View. Retrieved from: https://odv.awi.de 